Cell Research (2002); 12(1):47-54

http://www.cell-research.com

\title{
The inhibition of lung cancer cell growth by intracellular immuni- zation with LC-1 ScFv
}

\author{
Liang CHEN, Gang LI, Lei TANG, Jue WANG, Xi Rui GE* \\ Laboratory of Cellular Immunology, Institute of Biochemistry and Cell Biology, Shanghai Institutes for Biological \\ Sciences, Chinese Academy of Sciences, 320 Yueyang Road, Shanghai 200031, China
}

\begin{abstract}
A monoclonal antibody, LC-1, recognizing lung cancer associated common antigens was obtained in authors? laboratory. Its single chain Fv fragment ( $\mathrm{ScFv}$ ) named LC-1 ScFv was constructed based on recombinant phage displayed techniques. For expression on cell membrane, LC-1 ScFv was cloned into pDisplay vector, which directed the cloned gene to express as cell membrane bound protein. The resulting plasmid was sequenced and then introduced by the lipofectin method into a lung adenocarcinoma cell line SPC-A-1. G418 resistant cells were obtained by G418 selection. After transfection, LC-1 ScFv expression was observed by Western blot analysis and the expression of cognate antigens was down-regulated as shown in ELISA assay. SPC-A-1-pDisplay-ScFv cells grew in vitro at lower speed than the control intact cells and the cells transfected with vacant vector. Flow cytometry analysis detected a substantial increase in G1 phase and decrease in S phase in population of SPC-A-1-pDisplay-ScFv cells compared to SPC-A-1 and SPC-A-1-pDisplay cells. Semi-quantitative RT-PCR analysis showed that c-myc expression was down-regulated in SPC-A-1-pDisplay-ScFv cells. It seems that the antigens recognized by LC-1 may be in some way involved in a growth stimulating pathway and the antibody blocking of the function of the antigens shut down the pathway and thus down-regulate the expression of c-myc and growth of the cells.
\end{abstract}

Key words: $L C-1, L C-1 S c F v, S P C-A-1, p D i s p l a y$, lung cancer.

\section{INTRODUCTION}

Lung cancer remains the leading cause of cancer mortality in the world, accounting for more than one sixth of cancer deaths in the world[1]. Antibodies have been proved to be a powerful tool for the study of lung cancer. A monoclonal IgM antibody, LC-1, was obtained in our laboratory. It can react at a high rate with all four pathological types of lung cancers, including lung adenocarcinoma, lung squamous carcinoma, large cell lung cancer and small cell lung cancer, but not with normal and embryonic tissues [2]. In Western blot analysis, LC-1 detected three protein bands on cell surface of lung adenocarcinoma

*Corresponding author: Prof. Xi Rui GE, Tel: 086-21-643150302085 Fax: 086-21-64331090 e-mail: xiruige@sunm.shcnc.ac.cn Received Oct-15-2001 Revised Dec-6-2001 Accepted Dec-10-2001 cell line, SPC-A-1[3]. ABC staining revealed plenty of targeted antigens (LC-1Ags) on most lung cancer cells while few on normal tissues[2]. Further results indicated that LC-1 recognized the glyco-moiety of LC-1Ags(unpublished data). Experiments showed that when LC-1 bound SPC-A-1 cells, the antigenantibody complexes were internalized via the receptor-mediated endocytic pathway, concentrated in the multivesicular bodies and finally transported to lysosomes for final proteolysis[4]. However, little is known about the nature of LC-1Ags except that they are cell surface glyco-proteins. Moreover, how they function in the lung cancer remains to be solved. All of these indicated that LC-1 may be a useful tool for the study of lung cancer.

Intracellular immunization, which was first introduced in 1988[5], is defined as the inhibition or 
Inhibition of lung cancer cell growth by intracellular LC-1 ScFv

inactivation of the function of a molecule by the ectopic intracellular expression of antisense RNA, ribozyme, dominant negative mutants and others alike which recognize the molecule. ScFvs were applied to intracellular immunization shortly after the first report of ScFv. Persic L. et al reported the creation of a set of vectors which permitted the localization of ScFvs to different intracellular compartments: the endoplasmic reticulum (scFvEer), the nucleus (scFvE-nuclear), the mitochondria (scFvE-mit), the cytoplasm (scFvE-cyto), and as secreted proteins (scFvE-sec)[6]. Biocca S. and his colleagues reported the inactivation of p21ras in Xenopus laevis oocytes based on the intracellular expression of anti-p21ras ScFv genes. They found that cytosolic anti-p21ras ScFv not only markedly inhibited the $\mathrm{H} 1$ kinase activity induced by insulin but also blocked the ensuing meiotic maturation[7].

Here we report the construction of $\mathrm{ScFv}$ fragment of LC-1(named LC-1 ScFv, Genbank accession number AF348616), blocking of the function of LC-1Ags with intracellularly expressed LC-1 ScFv, the ensuing inhibition cell growth of lung cancer cells and its possible mechanism.

\section{MATERIALS AND METHODS}

\section{Cloning of $V_{H}$ and $V_{L}$ genes of $L C-1$}

LC-1 Hybridoma was raised and kept in our lab. Total RNA was extracted from $10^{7}$ cells with GIBCO-BRL TRIZOL Reagent (GIBCO Cat No. 15596, Rockville, USA) as directed by the manufacturers. cDNA was synthesized using GIBCO-BRL MMLV (GIBCO Cat. No. 28025-013): $10 \mu \mathrm{l}$ of $5 \times$ first strand buffer, DTT $0.01 \mathrm{M}, 1 \mathrm{mM}$ of each dNTPs, $5 \mu \mathrm{M}$ of random hexamer primers and RNA $20 \mathrm{mg} / \mathrm{L}$ in a total volume of $48 \mu \mathrm{l}$. The mixture was denatured at $70{ }^{\circ} \mathrm{C}$ for $10 \mathrm{~min}$ then chilled on ice for $2 \mathrm{~min}$. After adding $400 \mathrm{U}$ of reverse Transcriptase M-MLV, the mixture was incubated in $37{ }^{\circ} \mathrm{C}$ water bath for $1 \mathrm{~h}$ and then inactivated at $95{ }^{\circ} \mathrm{C}$ for $5 \mathrm{~min}$. Primers specific for framework 1 and joining regions were used[8], vhfor: TGA GGA GAC GGT GAC CGT GGT CCC TTG GCC CAG (3' of VH) and vhbak: AG GTC CAA CTG CAG GAG TCA GG (5' of VH), vlbak: GAC ATT GAG CTC ACC CAG TCT CCA (5' of VL gene), vlfor: G TTT GAT CTC GAG CTT GGT CCC (3' of VL gene). PCR was carried out as described[8]. Amplified fragments were cloned into pBluescript, and sequenced [ABI100 PRISMTM sequencer (PE co.)].

\section{Construction of LC-1 ScFv}

Linker primer: C TGG GGC CAA GGG ACC ACG GTC ACC GTC TCC TCA GGT GGA GGC GGT TCA GGC GGA GGT GGC TCT GGC GGT GGC GGA TCG GAC ATT GAG CTC ACC CAG TCT C[9] and primer vlfor were used to modify and amplify VL gene. $200 \mathrm{ng}$ of VH and modified VL gene fragments were each used to do SOE ligation. The resultant $\mathrm{ScFv}$ gene, named LC-1 ScFv, was amplified with vhbak and vlfor. Amplified LC-1 ScFv was cloned into pBluescript and sequenced.

\section{Affinity maturation of LC-1 ScFv}

Experiments were conducted according to the protocol given in users' manual (Cat No. 27-9401-01 Amersham Pharmacia Biotech. Co.). Briefly: LC-1 ScFv was modified and amplified with vhbaksfi: C ATG CCA TGA CTC GCG GCC CAG CCG CCG GCC ATG GCC CAG GTC CAA CTG CAG GAG TCA GG and vlfornot: GAG TCA TTC TGC GGC CGC CCG TTT GAT CTC GAG CTT GGT CCC. The modified and amplified LC-1 ScFv was digested with Sfi I (Cat No. R6391, Promega Co.) and Not I (Cat No. R6431, Promega co.), and subcloned into phagemid pCantab5E (Cat No. 27-9401-01, Amersham Pharmacia Biotech Co.). The resultant phagemid was transformed into F' E. coli TG1, rescued by KO7 helper phages. Recombinant phages were collected by PEG/NaCl (20\% PEG, $2.5 \mathrm{M} \mathrm{NaCl}) .10^{7}$ SPC-A- 1 cells were coated onto a plate, blocked with $3 \%$ NCS (new born calf serum)/PBS and 1012 recombinant phages were applied to the plate for panning, and washed 20 times with PBS and another 20 times with $1 \%$ NCS/0.1\% Tween 20/PBS. TG1 of OD600 0.3 was added to rescue the bound phages and reinfected for $2 \mathrm{~h}$ at $37 \mathrm{oC}$, the rescued phagemids were further subjected to another round of panning and three clones were sequenced.

\section{Introduction of plasmid into SPC-A-1 cell line}

Recombinant plasmid was introduced into lung adenocarcinoma cell line SPC-A-1 by lipofectin method as reported[10] with some modification. Briefly: Mature LC-1 ScFv gene was amplified and modified with vlforsacII (5' -ATG CAT CCG CGG CCG TTT GAT CTC CAA CTT GGT CCC-3' ) and vhbaksfi. The resultant LC-1 ScFv was digested with SfiI and SacII and cloned into identically digested pDisplay (Cat N0. V660-20, Invitrogen Co)(shown in Fig 1). The resulted recombinant plasmid was named pDisplay-ScFv. $15 \mu \mathrm{g}$ pDisplay-ScFv was dissolved into $400 \mu \mathrm{l}$ serum-free RPMI1640 medium and $15 \mu \mathrm{l}$ lipofectin (Cat No. 18292011, Gibco Co.) was dissolved into $400 \mu \mathrm{l}$ serum-free RPMI1640 medium. These two components were mixed together and incubated at $37^{\circ} \mathrm{C}$ for $1 \mathrm{~h}$. The mixture was used to incubate $5 \times 10^{5}$ overnight pre-incubated SPC-A-1 cells for $6 \mathrm{~h}$. The treated cells were incubated in RPMI1640/10\%NCS for $24 \mathrm{~h}$ and then kept in $10 \%$ NCS/G418/RPMI1640 for three weeks. Cell colonies were seen. Vacant $\mathrm{pDisplay} \mathrm{vector} \mathrm{and} \mathrm{sterile} \mathrm{water} \mathrm{were} \mathrm{also} \mathrm{used} \mathrm{to}$ transform the cell as controls. SPC-A-1 transfected with vacant pDisplay vector was labeled as SPC-A-1-pDisplay, SPC-A-1 transfected with pDisplay-ScFv as SPC-A-1-pDisplay-ScFv.

\section{ELISA assay of the expression of lung cancer associ- ated antigens}

$5 \times 10^{5}$ cells/well were coated onto each well of 96 -well plate. The plate was blocked with $6 \%$ NCS/PBS for $1 \mathrm{~h}$ at $37^{\circ} \mathrm{C}$, washed with $0.1 \%$ Tween-20/1\% NCS/PBS three times. $0.03 \mu \mathrm{g} / \mu \mathrm{l} \mathrm{LC}-1$ antibody was used to bind cells for an $\mathrm{h}$ at $37^{\circ} \mathrm{C}$ Horseradish peroxidase labeled anti-IgM second antibody (Cat No. A8786 m chain 
specific, Sigma Co.) was applied to bind LC-1 antibody. The plate was developed in OPD (O-phenylenediamine) substrate $(50 \mathrm{mM}$ $\mathrm{Na}_{2} \mathrm{HPO}_{4} 0.04 \%$ OPD, $0.03 \% \mathrm{H}_{2} \mathrm{O}_{2}, 24 \mathrm{mM}$ citrate). A490 was read by automatic reader.

\section{ECL western blot analysis of the expression of c-myc tagged LC-1 ScFv}

To assess the expression of LC-1 ScFv in the transfected SPCA-1, ECL Western blot analysis was conducted as reported[11] with some modification. Briefly: $5 \times 10^{6}$ cells were lysed in $500 \mathrm{ml}$ loading buffer (50 mM Tris-HCl pH 6.8, $100 \mathrm{mM}$ DTT, 2\% SDS, $10 \%$ glycerol). $20 \mathrm{ml}$ aliquot was subjected to $12 \%$ SDS-PAGE eletrophoresis. The separated proteins were transferred to nitrocellulose membrane in transfer buffer (20 mM Tris-HCl, $190 \mathrm{mM}$ Glycine, 20\% methanol, $\mathrm{pH}$ 8.3) using Mini Trans-blot transfer system (Bio-Rad) at $100 \mathrm{~V}$ for $1 \mathrm{~h}$. The membrane was blocked with $5 \%$ nonfat dried milk in TBST (Tris-buffered saline containing $0.05 \%$ Tween-20) and then incubated with mouse anti-human C-MYC first antibody (SC002051, BBST Co). After three washes in TBST, the membrane was incubated with peroxidaseconjugated goat anti-mouse second antibody (SC002050, BBST Co). The blot was incubated with ECL substrate (RPN2109, Amersham Pharmacia Biotech) to reveal the antigen bands and

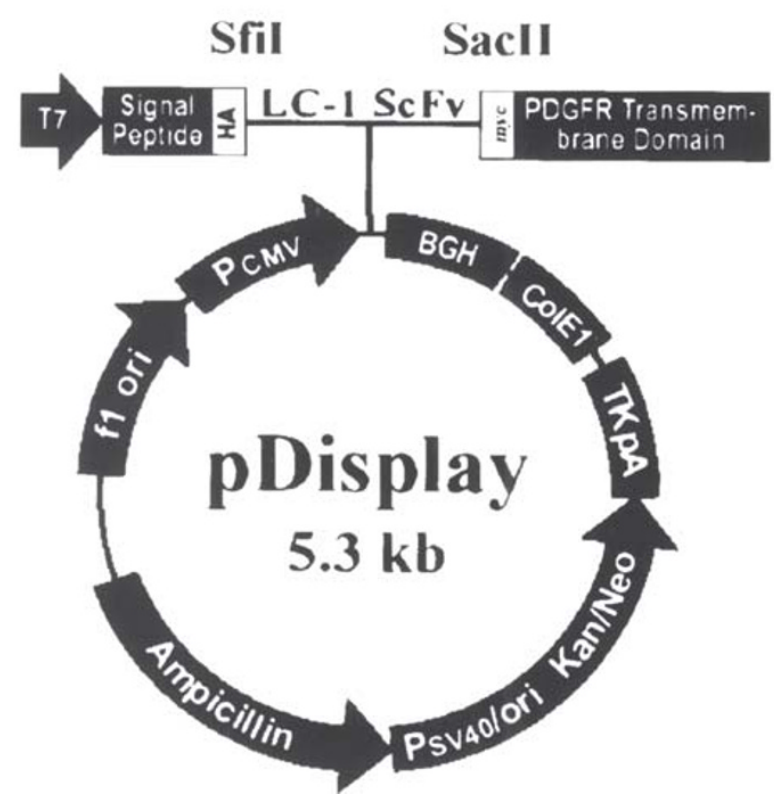

Fig 1. Representative map of pDisplay plasmid

Vacant pDisplay plasmid is digested with SfiI and SacII, and identically digested LC-1 ScFv fragment was ligated into it. SPC-A-1 was transformed with pDisplay, and pDisplay-ScFv. SPC-A-1-pDisplay-ScFv is the experimental series while SPCA-1 and SPC-A-1-pDisplay serve as control series.

pDisplay vector ensures that the cloned gene is expressed at high level as membrane-bound protein. the result was developed on x-ray film. 28-KD C-MYC tagged GUK domain of CASK protein (Genbank accession number AF035582) was used as positive control molecular marker.

\section{Determination of cell growth rate}

$5 \times 10^{5}$ SPC-A-1-pDisplay-ScFv cells were seeded in each flask ( 5 flasks a series). The number of cells was counted in hematocytometer per $24 \mathrm{~h}$. SPC-A-1 cells and SPC-A-1-pDisplay cells were used as control cells. The curve of cell growth rate of different series was drawn.

\section{Flow cytometry analysis of cell cycle}

Propidium iodide (PI) (Sigma, St. Louis, MO) stained cells were prepared and analyzed by flow cytometry (conducted by FACS laboratory of Shanghai Institute of Cell Biology, CAS). Briefly: $5 \times 10^{5}$ cells were seeded in each flask and kept at $37^{\circ} \mathrm{C}$ and $5 \% \mathrm{CO}_{2}$ for two days. Cells were then collected, fixed in citrate buffer at room temperature for $1 \mathrm{~h}$, centrifuged at $1000 \mathrm{~g}$ and resuspended in PBS at a final concentration of $6 \times 10^{6}$ cells $/ \mathrm{ml}$. Cells were stained using 1\% PI and 250 U RNase cocktail (RNase A, RNase T1, Ambion Corp., Austin, TX) and incubated in the dark at room temperature for $30 \mathrm{~min}$. Nuclear DNA content was measured based on PI fluorescence using a $488 \mathrm{~nm}$ argon laser and a BectonDickinson FACS Calibur flow cytometer (Becton-Dickinson Inc., San Jose, CA). Fluorescence data were collected in linear mode (8000 events) and the results were quantified using CELLQuest v1.01 (Becton-Dickinson Inc.). The percentages of $\mathrm{G}_{1}(1 \mathrm{~N}), \mathrm{S}$ (1$2 \mathrm{~N})$ and $\mathrm{G}_{2} / \mathrm{M}(2 \mathrm{~N})$ cells were calculated based on defined gates for each population.

\section{Semi-quantitative RT-PCR analysis of c-myc oncogene}

Total RNA was extracted using GIBCO-BRL TRIZOL Reagent (Cat No. 15596 Gibco Life Tech) as directed by manufacturers. cDNA was synthesized using GIBCO-BRL M-MLV (Cat No. 28025013, Gibco Life Tech). Semi-quantitative PCR was based on Chelly' s protocol[12] with some modifications. PCR amplification was performed on CEL-BIO Temperature Cycling System. PCR system: $12 \mu$ l of $10 \times$ reaction buffer, $0.25 \mathrm{mM}$ of each dNTPs, 0.75 pmol of each sense and antisense primers (C-myc sense (5' GTT TTC CAA CTC CGG GAT CTG-3' ) and c-myc antisense (5’ -AAG ACT CCA GCG CCT TCT CTC-3' )(synthesized by Sangon Co.) for amplification of c-myc oncogene fragment and Gapdhfor and gapdhbak (kindly provided by Dr Changling LI, Institute of Cell Biology, CAS) for amplification of GAPDH fragment), and $6 \mathrm{ml}$ of $\mathrm{cDNA}$. Adjust total volume to $117 \mu \mathrm{l}$ with double-distilled $\mathrm{H}_{2} \mathrm{O}$. The mixture was denatured at $95{ }^{\circ} \mathrm{C}$ for $5 \mathrm{~min}$, then $3 \mu \mathrm{l}$ of Taq DNA polymerase ( $3 \mathrm{U}$ per $\mathrm{m}$ l, Cat No. MM0962, Sino-American Biotechnology Company, China) was added as a "hot start" method[13] to eliminate non-specific annealing. GAPDH was used as an internal constant standard. PCR was performed in the following condition: denaturation for $45 \mathrm{~s}$ at 94 ${ }^{\circ} \mathrm{C}$, annealing for $45 \mathrm{~s}$ at $59{ }^{\circ} \mathrm{C}$, and extension for $45 \mathrm{~s}$ at $72{ }^{\circ} \mathrm{C}$. Initially, c-myc gene was amplified for 7-13 cycles and then the primers for internal standard, GAPDH, were added by the 
Inhibition of lung cancer cell growth by intracellular LC-1 ScFv

“primer-dropping” method[14]. After another 14-17 cycles, 17 $\mu \mathrm{l}$ of template of PCR reaction was collected from the following different cycles and templates were then electrophoresed through $1 \%$ agarose gels, and stained with ethidium bromide and photographed. The density of target bands was measured by FURI Smartview-2000 (Shanghai FURI Science and Technology Co, Ltd,). The optimal numbers of PCR cycles were determined.

\section{RESULTS}

Sequences of $V H$ and $V L$ and affinity maturation of $L C-1 \mathrm{ScFv}$

In electrophoresis, the isolated total RNA sample gave out three sharp bands, demonstrating the integrity of RNA extracted from hybridoma LC-1 (data not shown). PCR products of $\mathrm{V}_{\mathrm{H}}$ gene (Genbank accession number AF348614) and $\mathrm{V}_{\mathrm{L}}$ gene Fig 2 (Genbank accession number AF348615) can be amplified from reverse transcripted cDNAs. Electrophoresis showed that they were of expected molecular size. Sequences were aligned on NCBI
BLAST (http://www.ncbi.nlm.nih.gov/blast/blast. cgi). Results showed that cloned $\mathrm{V}_{\mathrm{H}}$ and $\mathrm{V}_{\mathrm{L}}$ gene matched antibody sequence well. Sequence of LC-1 ScFv (Genbank accession number AF348616) showed that $\mathrm{V}_{\mathrm{H}}$ and $\mathrm{V}_{\mathrm{L}}$ gene were successfully spliced.

After affinity maturation using phage-display

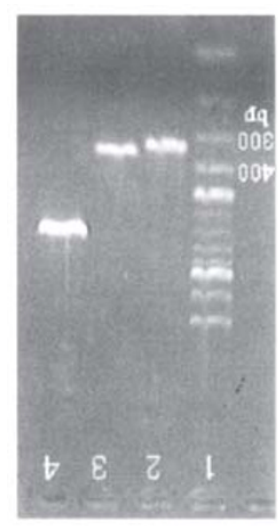

Fig 2. Electrophoresis of clone $\mathrm{VL}, \mathrm{VH}$ and $\mathrm{ScFv}$ Lane 1 100bp marker; Lane 2 VL gene fragment; Lane $3 \mathrm{VH}$ gene fragment; Lane $4 \mathrm{ScFv}$ gene fragment.

Results showed that VH and VL, and LC- $1 \mathrm{ScF} v$ gene were of expected molecular size. Sequences of these genes were registered in Genbank (accession number: 348614, 348615, 348616).

\begin{abstract}
$\mathrm{V}_{\mathrm{H}}$ :
CAG GTC CAA CTG CAG GAG TCA GGG GGG GGC TTA GTG AAG CCT GGA GGG TCC CTG AAA CTC TCC TGT GCA GCC TCT GGA TTC ACT TTC AGT AGCTAL GCC ATG TCI TGG GTT CGC CAG GCT CCA GAG AAG AGG CTG GAG TGG GTC GCA ICC AII AAT TAT GGI GGL GACACC TAC TAT CCA GACAAT GTG AAGGGC CGA TTC ACC ATC TCC AGA GAT AAT GCC GGG AAC ATC CTG TTC CTG CAA ATG AGC AGT CTG AGG TCT GAG GAC ACG GCC ATG TAT TAC TGT GCA AGA GTI TCG TAC TACGGICGT ACC TAC CAC TAT GCT ATG GAC TAC TGG GGC CAA GGG ACC ACG GTC ACC GTC TCC TCA (with CDRs underlined)
\end{abstract}

Deduced amino acid sequence of $\mathrm{V}_{\mathrm{H}}$ :

VQLQE SGGGL VKPGG SLKLS CAASG FTFSS YAMSW VRQAP EKRLE WVASINYGGD TYYPDNVKGR FTISR DNAGN ILFLQ MSSLR SEDTA MYYCA RVSY YGRTYHYAMDYWGQG TTVTV SS

$\mathrm{V}_{\mathrm{L}}$ :

GAC ATT GAG CTC ACC CAG TCT CCA GCA CTC ATG GCT GCA TCT CCA GGG GAG AAG GTC ACC ATC ACC TGC AGT GTC AGC TCA AGT ATA AGT TCC AGC AACTIACAC TGG TAC CAG CAG AAG TCA GAA ACC TCC CCC AAA CCC TGG ATC IAT GGC ACA TCC AAC CTG GCT TCI GGA GTC CCT GTT CGC TTC AGT GGC AGT GGA TCT GGG ACC TCT TAT TCT CTC ACA ATC AGC AAC ATG GAG GCT GAA GAT GCT GCC ACT TAT TAC TGT CAA CAG TGG AGT AGT TAC CCC CTC ACG TTC GGC TCG GGG ACC AAG TTG GAG ATC AAA CGG (with CDRs underlined)

Deduced amino acid sequence of $\mathrm{V}_{\mathrm{L}}$ :

DIELT QSPAL MAASP GEKVT ITCSV SSSIS SSNLH WYQQK SETSP KPWIY GTSNLASGVP VRFSG SGSGT SYSLT ISNME AEDAA TYYC @QWSS YPLTF GSGTK LEIKR

Fig 3. Nucleotide sequence and deduced amino acid sequence of VH and VL 
technique, three clones screened out were sequenced, and they gave out same sequences. No mutation was detected. (as shown in Fig 3)

\section{Introduction of plasmid into SPC-A-1}

Using lipofectin, foreign plasmid could be easily introduced into SPC-A-1 cell. Hundreds of clones were formed per $10^{5}$ cells. SPC-A- 1 cells treated with sterile water instead of plasmid in transformation died out under the selecting pressure of G418 after 4 changes of media, while hundreds of colonies were formed in SPC-A-1 treated with pDisplay and pDisplay-scfv.

Expression of lung cancer associated surface antigens on different cells detected by ELISA

SPC-A-1 cell and SPC-A-1 cells transfected with vacant $\mathrm{pDisplay}$ vector (SPC-A-1-pDisplay) expressed high level of LC-1Ags, while cells transformed with pDisplay-ScFv expressed few LC-1Ags detected by ELISA. (as shown in Fig 4)

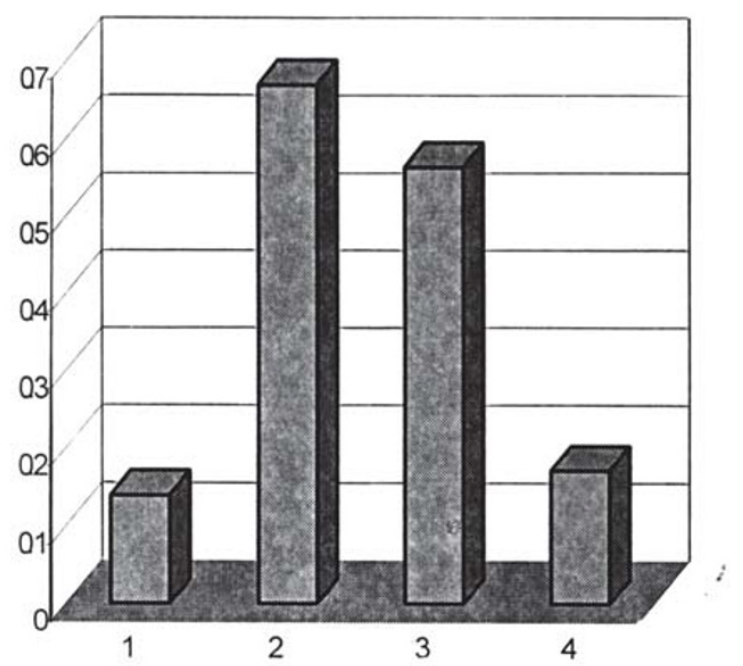

Fig 4. Elisa assay of the expression of LC-1TAs on different cell series

1, A490 of PBS control; 2, A490 of SPC-A-1 cell; 3, A490 of SPC-A-1-pDisplay; 4, A490 of SPC-A-1-pDisplay-ScFv. Results showed that numerous epitope sites of LC-1TAs on SPCA-1-pDisplay-ScFv cell were bound with LC-1 ScFv.

LC-1 ScFv expression in transformed cells by ECL Western blot assay

To confirm that the lowered level of the expression of LC-1Ags was caused by the expression of
LC-1 ScFv, we assayed the LC-1 ScFv expression by Western blot with anti-c-myc antibody, for pDisplay vector could endow a c-myc tag on the c-terminal of inframe protein as indicated in the representative

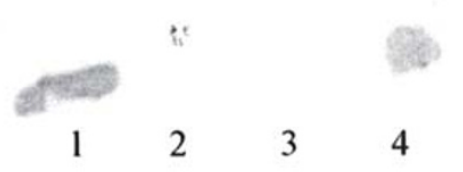

Fig 5. Western blot analysis of LC-1 ScFv expression in transfected cells

Lane 1, blot of molecular maker (28,000 Da); Lane 2, blot of SPC-A-1; Lane 3, blot of SPC-A-1-pDisplay; Lane 4, blot of SPC-A-1-pDisplay-scfv.

Results showed the expression of LC-1 ScFv in SPC-A-1pDisplay-scfv cells.

map of the plasmid. Western blot results (Fig 5) showed that SPC-A-1-pDisplay-scfv gave a strong signal of c-myc tag but SPC-A-1 cells and SPC-A-1pDisplay cells lacked of the $30 \mathrm{KD}$ band in ECL Western blot assay.

\section{Comparison of cell growth rate}

An interesting phenomenon was that among these different kinds of cells, the SPC-A-1-pDisplay-ScFv cells grew much slower than SPC-A-1 cells or SPCA-1-pDisplay cells (Fig 6). It showed that when SPCA-1 or SPC-A-1-pDisplay cells reached overconfluence, the cell growth of SPC-A-1-pDisplay$\mathrm{ScFv}$ only reached $40-50 \%$.

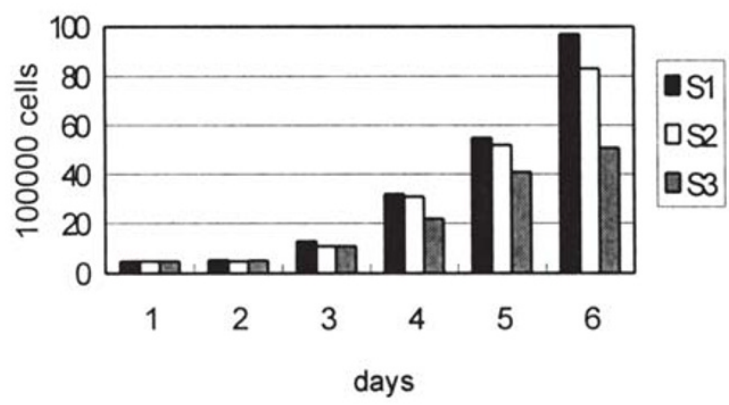

Fig 6. Time dependent curve of growth rate of different cell series

$\mathrm{S} 1$, growth rate of SPC-A-1 cells; S2, growth rate of SPC-A-1pDisplay cells; S3, growth rate of SPC-A-1-pDisplay-ScFv cells.

Results showed that SPC-A-1-pDisplay-ScFv grew slower than other two cell series. 
Inhibition of lung cancer cell growth by intracellular LC-1 ScFv

Flow cytometry analysis of cell cycle

From Tab 1, Results revealed a substantial increase of cell percentage in $G_{1}$ phase and decrease in $\mathrm{S}$ phase in population of SPC-A-1-pDisplay-ScFv cells compared to SPC-A-1 and SPC-A-1-pDisplay cells. This indicated that the proliferating SPC-A-1pDisplay-ScFv cells were fewer than that of SPC-A1 and SPC-A-1-pDisplay cells.

Tab 1. Flow cytometry analysis of cell cycle

\begin{tabular}{|c|c|c|c|}
\hline & $\begin{array}{c}\text { Percentage } \\
\text { of } \mathrm{G}_{0}-\mathrm{G}_{1}\end{array}$ & $\begin{array}{c}\text { Percentage } \\
\text { of } \mathrm{G}_{2}-\mathrm{M}\end{array}$ & $\begin{array}{c}\text { Percentage } \\
\text { of } \mathrm{S}\end{array}$ \\
\hline SPC-A-1 & 63.22 & 13.50 & 23.28 \\
\hline $\begin{array}{l}\text { SPC-A-1- } \\
\text { pDisplay }\end{array}$ & 61.51 & 13.06 & 25.43 \\
\hline $\begin{array}{l}\text { SPC-A-1- } \\
\text { pDisplay- }\end{array}$ & $\begin{array}{l}67.83 \\
\mathrm{cFv}\end{array}$ & 11.40 & 20.77 \\
\hline
\end{tabular}

Analysis of c-myc oncogene expressed in these three different kinds of cells by semi-quantitative PCR

In Fig 7 it was indicated by semi-quantitative PCR analysis that c-myc expression was lower in SPC-A-1-pDisplay-scfv than that in SPC-A-1 or SPC-A-1-pDisplay cells. The results showed that cmyc gene expression was down-regulated in SPCA-1-pDisplay-scfv cell. It means that the lower growth rate of SPC-A-1-pDisplay-ScFv may be cor-

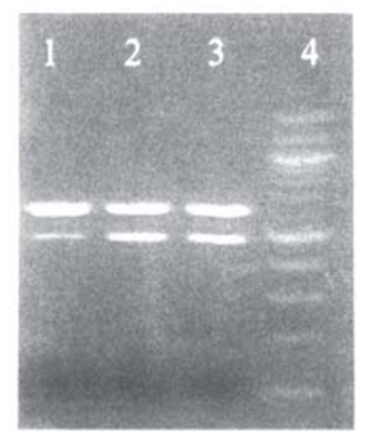

Fig 7. Semi-quantitative PCR sample of different cell series Lane 1, RT-PCR sample of SPC-A-1-pDisplay-ScFv, c-myc fragment below the GAPDH fragment; Lane 2, RT-PCR sample of SPC-A-1-pDisplay, c-myc fragment below GAPDH fragment; Lane 3, RT-PCR sample of SPC-A-1, c-myc fragment below GAPDH fragment; Lane 4, 100 bp ladder molecule marker.

Results showed expression of c-myc was down-regulated in SPC-A-1-pDisplay-ScFv cells while relatively high in SPC-A1 cell and in SPC-A-1-pDisplay cells. related with down-regulation of c-myc gene in these cells.

\section{DISUCSSION}

LC-1Ags are shared by different lung cancers, as reported earlier by our Lab[2]. In SPC-A-1 cells, the antigens appear to be 51,70 , or $91 \mathrm{KD}[3]$. Data show there are $7.2 \times 10^{4}$ antigen sites per SPC-A-1 cell [15].

Functionally blocking a specific protein has been succeeded with antagonists[16], antisense oligo nucleotide[17], and antibody[18]. Since Biocca et. al. introduced the idea of intracellular immunization with $\mathrm{ScFv}$, many cellular proteins have been functionally blocked with $\mathrm{ScFv}$ [7].

$\mathrm{V}_{\mathrm{H}}$ and $\mathrm{V}_{\mathrm{L}}$ gene of LC- 1 have been cloned and their sequences were confirmed by twice fluorescent sequencing. LC-1 ScFv was constructed. After affinity maturation, no mutations occurred in sequence of $\mathrm{VH}$ and $\mathrm{VL}$ gene. It could be due to high binding activity of LC-1 antibody. It can effectively compete with other phage-display antibodies for binding to the immobilized SPC-A-1 cells and thus all the picked clones were identical with original sequence. We cloned the LC-1 ScFv gene into pDisplay to functionally block the cognate surface glycoproteins. The pDisplay vector features three elements: human cytomegalovirus (CMV) immediate-early promoter/ enhancer which permits efficient, high level expression of the recombinant protein, the murine Ig kchain leader sequence at the $\mathrm{N}$-terminus and platelet derived growth factor receptor transmembrane domain (PDGFR-TM) at the C-terminus, which anchors the fusion protein to the plasma membrane and myc epitope which allows detection of the fusion protein with anti-myc antibody. In western blot analysis, high expression of LC-1 ScFv was detected in SPC-A-1-pDisplay-ScFv cells. In ELISA assay, no remarkable difference in LC-1Ags was detected between A490 of SPC-A-1-pDisplay-ScFv and that of PBS control, while A490 of SPC-A-1 and SPC-A-1pDisplay cells was remarkably high, indicating that numerous epitopes were bound with LC-1 ScFvs.

Most probably, mechanism implicated in the low detection of LC-1Ags is that the immunocomplexes of LC-1 ScFv and LC-1Ags were internalized via the receptor-mediated endocytic pathway, concentrated 
in the multivesicular bodies and transported to lysosomes for final proteolysis, similar to the report by Xie W. et al[4]. But we are also aware of another possibility that the immunocomplexes remained on the cell membrane. But LC-1Ags were blocked by LC-1 ScFv, similar to the report by Biocca S. et al [7].

In our experiments, SPC-A-1-pDisplay-ScFv cells were found to grow slower than SPC-A-1 and SPCA-1-pDisplay cells. Result of flow cytometry analysis elucidated that there were fewer proliferating SPC-A-1-pDisplay-ScFv cells than that of SPC-A-1 and SPC-A-1-pDisplay cells. In our study, expression of c-myc was found to be down-regulated in SPC-A-1-pDisplay-ScFv cells, while remained high in SPC-A-1 and SPC-A-1-pDisplay cells as quantified by semi-quantitative RT-PCR analysis.

How is the blocking of LC-1Ags by LC- $1 \mathrm{ScFv}$ connected with the slowing-down of cell growth and c-myc down-regulation? Studies have shown that many growth factors or regulatory peptides and their receptors are expressed by cancer or adjacent normal cells in the lung, thus providing a series of autocrine or paracrine growth stimulatory loops[19]. Further studies revealed that formation of soft agar clones in vitro and the in vivo growth of xenografts of lung cancer cells in nude mouse were inhibited by neutralizing monoclonal antibody that blocked these stimulatory loops[20],[21]. Three best characterized autocrine systems in the lung cancer involve GRP/BN and their receptors[20], Neu differentiation factors (NDF) and their ERBB family receptors [22], and EGF/TGFa and their receptors[23]. The fact that lung adenocarcinoma cell line SPC-A-1 grows more slowly when intracellularly expressed LC-1 ScFvs block surface expression of LC-1Ags and that soft agar colony formation of SPC-A-1-pDisplay$\mathrm{ScFv}$ is inhibited (data not published) are highly similar to the inhibition of soft agar colony formation by antibody disturbance as reported[20],[21]. This suggests that LC-1Ags of SPC-A-1 are possibly involved in an autocrine growth stimulatory loop which stimulates the growth of the cells. When LC-1Ags are blocked by LC-1 ScFv, thus leading to the shutdown of this autocrine loop, cells grow at lower speed. Most growth factor receptors are in some way involved in the signal transduction process, such as GRP/BN receptors belong to the G- protein coupled receptor superfamily[24].

Myc proteins are transcription factors of helixloop-helix/leucine zipper family that activate transcription as obligate heterodimers with a partner, protein Max[25]. A list of candidate genes activated at transcriptional level by myc was compiled, which contained a number of genes required for cell proliferation[26]. Myc activity is controlled at multiple levels by signal transduction cascades: one such level is c-myc transcription that is strongly induced by growth factors. A second level of control is through proteins that interact with the N-terminal of myc [27]. c-myc, among the so called class II cancer genes, is not altered at DNA level, but affects the phenotype of the host cells by changes in expression[28]. c-myc oncogene, a key oncoprotein in regulation of cell proliferation and apoptosis[29], was reported to be up-regulated in lung cancer cells[30]. MYC protein promotes normal cell growth and proliferation through direct activation of genes involved in DNA synthesis, RNA metabolism and cell-cycle progres$\operatorname{sion}[24]$.

We hypothesize that in SPC-A-1, LC-1Ags seem to pick up extracellular signals and then up- regulate the c-myc expression through their signal transduction pathway and thus promote cell growth. When the antigens are blocked, the signal transduction pathway is shut down, leading to downregulation of the c-myc expression and ensuing slowing down of cell growth.

Our experiments, together with our previous studies[31],[32] showed LC-1Ags on SPC-A-1 cells could be a good target for lung cancer diagnosis and immunotherapy.

\section{ACKNOWLEDGMENTS}

This work was supperted by Sciense and Technology Promoting Foundation of Shanghai No. 984419071.

\section{REFERENCES}

[1] Hoffman PC, Mauer AM, Vokes EE. Lung cancer. Lancet 2000; 355(9202):479-85.

[2] Ge XR, Wang J, Lin SJ, Yu NX, Che YF, Gu Y. McAb LC-1 against human lung cancer. Acta Biologiae Experimentalis Sinica 1989; 22(3):359-65.

[3] Lin SJ, Ge XR, Wang J, Gu Y. Studies on antigens of human lung adenocarcinoma with McAb LC-1. Acta Biologiae Experimentalis Sinica 1990; 23(2):233-8. 
[4] Xie W, Zhang RX, Ge XR. Internalization of tumor associated antigen on human lung adenocarcinoma cell line SPCA-1 by McAb LC-1. Acta Biologiae Experimentalis Sinica, 1996; 29(3):207-19.

[5] Staeheli P. Intracellular immunization: A new strategy for producing disease-resistant transgenic livestock? Trends Biotechnol 1991; 9(3):71-2.

[6] Persic L, Righi M, Roberts A, Hoogenboom HR, Cattaneo A, Bradbury A. Targeting vectors for intracellular immunisation. Gene 1997; 187(1):1-8.

[7] Biocca S, Pierandrei-Amaldi P, Campioni N, Cattaneo A. Intracellular immunization with cytosolic recombinant antibodies. Biotechnology (N Y) 1994; 12(4):396-9.

[8] Orlandi R, Gussow DH, Jones PT, Winter G. Cloning immunoglobulin variable domains for expression by the polymerase chain reaction. Proc Natl Acad Sci 1989; 86 (10):3833-7.

[9] Peter K, Graeber J, Kipriyanov S et al. Construction and functional evaluation of a single-chain antibody fusion protein with fibrin targeting and thrombin inhibition after activation by factor Xa. Circulation 2000; 101(10): 1158-64 .

[10] Qin WX, DF Wan, FY SUN et al. Cloning and characterization of a novel gene (C17orf25) from the deletion region on chromosome $17 \mathrm{p} 13.3$ in hepatocellular carcinoma. Cell Research 2001; 11(3):209-16.

[11] Kong WH, Z Cu, JN Lu, JK Tso. Temperature dependent expression of cdc2 and cyclin B1 in spermatogenesis. Cell Research 2000; 10(4):289-302.

[12] Chelly J, Kaplan JC, Maire P, Gautron S, Kahn A. Transcription of the dystrophin gene in human muscle and non muscle tissues. Nature 1988; 333:858-60.

[13] Ailenberg M, Silverman M. Controlled hot start and improved specificity in carrying out PCR utilizing touchup and loop incorporated primers (TULIPS). Biotechniques 2000; 29(5):1018-20, 1022-4.

[14] Vehaskari VM, Hempe JM, Manning J, Aviles DH, Carmichael MC. Developmental regulation of ENaC subunit mRNA levels in rat kidney. Am J Physiol 1998; 274 (6 Pt 1):C1661-6.

[15] Li M, Lian BJ, Ge XR. Study on binding characteristics of 125I-labeled McAb LC-1 to lung adenocarcinoma cells in vitro and in vivo. Acta Biologiae Experimentalis Sinica 1992; 25(1):31-8.

[16] Tramontana M, Lecci A, Meini S, Montserrat X, Pascual J, Giuliani S, Quartara L, Maggi CA. Differences between peptide and nonpeptide $\mathrm{B}(2)$ bradykinin receptor antagonists in blocking bronchoconstriction and hypotension induced by bradykinin in anesthetized Guinea pigs. J Pharmacol Exp Ther 2001; 296(3):1051-7.

[17] Rajagopal S, Moskal TL, Wang H, Chakrabarty S. Efficacy and specificity of antisense laminin chain-specific expression vectors in blocking laminin induction by
TGFbeta1: Effect of laminin blockade on TGFbeta1mediated cellular responses. J Cell Physiol 1999; 178 (3):296-303.

[18] Yamada T, Okafuji T, Ohta K, Handwerker C, Drescher $\mathrm{U}$, Tanaka H. Analysis of ephrin-A2 in the chick retinotectal projection using a function-blocking monoclonal antibody. J Neurobiol 2001; 47(4):245-54.

[19] Viallet J, Sausville EA. Involvement of signal transduction pathways in lung cancer biology. J Cell Biochem Suppl 1996; 24:228-36.

[20] Cuttitta C, Carney DN, Mulshine J, Moody TW, Fedorko J, Fischler A, Minna JD. Bombesin-like peptides can function as autocrine growth factors in human small-cell lung cancer. Nature 1985; 316(6031):823-6.

[21] Halmos G, Schally AV. Reduction in receptor for bombesin and epidermal growth factor in Xenografts of human small cell lung cancer after treatment with bombesin antagonist RC-3095. PNAS 1997; 94(3):95660.

[22] Alroy I, Yarden Y. The ErbB signaling network in embryogenesis and oncogenesis: signal diversification through combinatorial ligand-receptor interactions. FEBS Lett 1997; 410(1):83-6.

[23] Damstrup L, Rygaard K, Spang-Thomen M, Poulsen HS. Expression of the epidermal growth factor receptor in human small cell lung cancer cell lines. Cancer Res 1992; 52(11):3089-93.

[24] Fathi Z, Way JW, Corjay MH, Viallet J, Sausville EA, Battey JF. Bombesin receptor structure and expression in human lung carcinama cell lines. J Cell Biochem (suppl) 1996; 24:237-46.

[25] Henriksson M, Luscher B. Proteins of the Myc network: essential regulators of cell growth and differentiation. Adv Cancer Res 1996; 68:109-82.

[26] Grandori C, Eisenman RN. Myc target genes. Trends Biochem Sci 1997; 22(5):177-81.

[27] Bouchard C, Staller P, Eilers M. Control of cell proliferation by Myc. Trends Cell Biol 1998; 8(5):202-6.

[28] Sager R. Expression genetics in cancer: Shifting the focus from DNA to RNA, PNAS 1997; 94:952-25.

[29] Sekido Y, Fong KM, Minna JD. Progress in understanding the molecular pathogenesis of human lung cancer. Biochim Biophys Acta 1998; 1378(1):F21-59.

[30] Pelengaris S, Rudopph B, Littlewood T. Action of Myc in vivo-proliferation and apoptosis. Current opinion in Genetics and Development 2000; 10:100-5.

[31] Lin SJ, Wang J, Lin XK, Fan ZJ, Ge XR. Study on immunoradiological location of human lung cancers with McAb LC-1 IgM fragment. Shanghai J Immunol 1998; 18(4):201-3, 214.

[32] Lin SJ, Zeng L, Zhong GR, Ge XR. Studies on treatment of nude mice bearing human lung cancer with 90Y-LC-1. J Shanghai Med Univer 1999; 26(3):206. 